DE

M E D I C I N A

T R O P I C A L

$\mathrm{DE}$

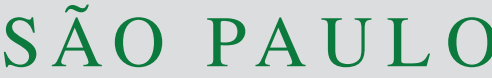

JOURNAL OF THE SÃO PAULO INSTITUTE OF TROPICAL MEDICINE

'Universidade Federal de Alfenas, Instituto de Biociências, Departamento de Microbiologia e Imunologia, Alfenas, Minas Gerais, Brazil

'Universidade Federal de Alfenas, Faculdade de Ciências Farmacêuticas, Departamento de Alimentos e Medicamentos, Alfenas, Minas Gerais, Brazil

3Universidade de São Paulo, Faculdade de Ciências Farmacêuticas, São Paulo, São Paulo, Brazil

Correspondence to: Amanda Latercia Tranches Dias

Department of Microbiology and Immunology, Institute of Biosciences, Rua Gabriel Monteiro da Silva, 700, centro, CEP 37130-000, Alfenas, Minas Gerais, Brazil Tel: +55 35 3701-9569.

E-mail: amandaltdias@gmail.com

Received: 19 September 2018

Accepted: 19 February 2019

\section{Ozone against Pseudomonas aeruginosa biofilms in contact lenses storage cases}

\author{
Josidel Conceição Oliver ${ }^{(1)}$, Paula Anatália Pereira Bredarioli1,2,3, Fabrício \\ Damasceno Leandro, ${ }^{1,2}$, Carla Benedini Ribeiro Jorge Ferreira1, Sandra Maria \\ Oliveira Morais Veiga ${ }^{2}$, Amanda Latercia Tranches Dias ${ }^{(1}$
}

\section{ABSTRACT}

Pseudomonas aeruginosa is associated with ocular infections such as keratitis. Multipurpose contact lens solutions can be used for washing, disinfection and storage of contact lenses, however, $P$. aeruginosa biofilm disinfection by this method is unsatisfactory. The present study aimed to investigate the effectiveness of ozonated water in reducing $P$. aeruginosa colony count. Lenses kept in storage cases were contaminated with $P$. aeruginosa and disinfected using ozonized water, chlorhexidine, ultrasound and multipurpose solutions. The multipurpose solutions and ultrasound methods reduced colony count from 1.17 to $1.63 \log _{10} \mathrm{CFU} / \mathrm{cm}^{2}$ (92.93\% to $97.31 \%$ ), respectively, of $P$. aeruginosa biofilm cell viability when compared to the positive control. Both, ozonated water and chlorhexidine showed $7.42 \log$ reduction in the number of viable cells of $P$. aeruginosa biofilm. As compared to chlorhexidine, ozonized water did not depose any known toxic residues, so that we recommend it as an alternative disinfectant solution for contact lenses storage cases.

KEYWORDS: Ozonized water. Chlorhexidine. Ultrasound. Multipurpose solutions. Decontamination.

\section{INTRODUCTION}

Pseudomonas aeruginosa is a pathogenic microorganism with clinical importance, associated with hospital infections and microbial keratitis. This bacterium has the capability to adhere, disseminate and form biofilms on medical devices such as catheters and contact lenses ${ }^{1-3}$. It is important that contact lenses users have effective hygiene practices to minimize contamination and biofilm formation in lenses and their storage cases ${ }^{4}$. Multipurpose solutions are commonly used as active agents to decrease the accumulation of proteins on the surface of contact lenses and their storage cases. These solutions should eliminate microorganisms during disinfection and storage of contact lenses, but previous studies have demonstrated that several multipurpose solutions have not been capable of eliminating high concentrations of microorganisms ${ }^{5,6}$. Therefore, it is important to search for alternative agents for effectively disinfecting contact lenses and storage cases. In this study, we analyzed the effectiveness of alternative methods, mainly ozonized water, as compared to two multipurpose solutions, for the removal of $P$. aeruginosa biofilms. 


\section{METHODS}

\section{Growing of $P$. aeruginosa biofilm}

Pseudomonas aeruginosa ATCC 27853 bacteria were grown in tubes containing Brain Heart Infusion Agar (HiMedia ${ }^{\circledR}$, HiMedia Laboratories, India) at $37^{\circ} \mathrm{C}$ for $24 \mathrm{~h}$. Cultures were subsequently inoculated in sterile saline solutions $(0.85 \% \mathrm{NaCl}$, Merck, Germany) to obtain a turbidity equivalent to 1 on the McFarland, $3.0 \times 10^{8}$ colony forming unit (CFU) per $\mathrm{mL}$, according to Zhu et al. ${ }^{7}$ (with some modifications). The bacterial suspension was diluted 1:100 in Mueller Hinton broth $\left(\right.$ HiMedia $^{\circledR}$, HiMedia Laboratories, India) and $1 \mathrm{~mL}$ was transferred to each compartment of contact lenses storage cases. The lenses storage cases were maintained $24 \mathrm{~h}$ at $25^{\circ} \mathrm{C}$ favoring the biofilm formation. The experiments were designed with positive and negative microbial growth controls, performed in triplicate with repetition on two different days.

\section{Disinfection of biofilms}

The lenses storage cases were washed three times with 2 $\mathrm{mL}$ of saline $(0.85 \% \mathrm{NaCl})$ and then were disinfected with the following techniques or disinfectant solutions.

Multipurpose solution 1: it is a sterile isotonic solution containing boric acid, EDTA, sodium borate, sodium chloride, DYMED ${ }^{\circledR}$ (polyaminopropyl biguanide $0.0001 \%$ ), HYDRANATE ${ }^{\circledR}$ (hydroxyalkylphosphonate $0.03 \%$ ) and $1 \%$ poloxamine (Renu MultiPlus ${ }^{\circledast}$ Fresh Lens Comfort $^{\mathrm{TM}}$, Bausch \& Lomb, Brazil). The disinfection with multipurpose solution 1 was carried out for $4 \mathrm{~h}$ following the manufacturer's specifications.

Multipurpose solution 2: it is a sterile, buffered, isotonic, aqueous solution containing sodium citrate, sodium chloride, sodium borate, propylene glycol, TEARGLYDE ${ }^{\circledR}$ proprietary dual action reconditioning system (TETRONIC ${ }^{\circledR}$ 1304, nonanoyl ethylenediaminetriacetic acid) with POLYQUAD $^{\circledR}$ (polyquaternium-1) $0.001 \%$ and ALDOX $^{\circledast}$ (myristamidopropyl dimethylamine) $0.0005 \%$ preservatives (Opti-Free ${ }^{\circledast}$ Replenish ${ }^{\circledR}$ Multi-Purpose Contact Lens Solution, Alcon, Brazil). The disinfection with multipurpose solution 2 was carried out by incubation for $6 \mathrm{~h}$, following the manufacturer's specifications.

Ultrasound: the ultrasound was applied in a vat with sterile water at frequency of $40 \mathrm{kHz}$, for $20 \mathrm{~min}$ (ALT Sonic Clean, ALT Equipamentos, Brazil).

Ozone: the ozone was produced using medical oxygen (White Martins, Brazil) and an ozone generator (BrazilOzônio, BRO3-3, Brasil Ozônio, Brazil) of $10 \mathrm{~g} / \mathrm{h}$. The pressure was set to $0.5 \mathrm{kgf} / \mathrm{cm}^{2}$ and flow of $4 \mathrm{mg} / \mathrm{L}$ for
$20 \mathrm{~min}$. The determination of residual ozone concentration was performed by indirect iodometric method, using $0.005 \mathrm{~N}$ sodium-thiosulfate (Merck, Germany) as a titrant ${ }^{8}$. The distilled water was saturated with ozone for $20 \mathrm{~min}$ before the experiment and saturation maintained during the disinfection process.

Chlorhexidine: the chlorhexidine gluconate solution (University Pharmacy UNIFAL-MG, Brazil) was used at the concentration of $0.12 \%$ for $20 \mathrm{~min}$.

\section{Microbial analysis}

The biofilm cell viability was evaluated after the attempted disinfection of biofilms. Each compartment of the storage cases was washed with $2 \mathrm{~mL}$ of saline solution, three times. A swab was used to sample the surfaces, as follows: surface was scrubbed ten times vertically and horizontally, then the swab was placed in a saline tube and vortexed for $10 \mathrm{~s}$. The bacterial suspension derived from formed biofilms was diluted and inoculated on the surface of cetrimide agar (HiMedia ${ }^{\circledR}$, HiMedia Laboratories, India). The plates were incubated at $35^{\circ} \mathrm{C}$ for $24 \mathrm{~h}$ and the results were expressed as $\mathrm{CFU} / \mathrm{cm}^{2}$ (area of the cavity of the contact lenses storage cases $=2.9845 \mathrm{~cm}^{2}$ ). The determination of the logarithmic reduction of growth in each treatment and the control was calculated by the following equation $[\log$ reduction $=$ $\log _{10}\left(\right.$ initial CFU $\left./ \mathrm{cm}^{2}\right)-\log _{10}\left(\right.$ final $\left.\left.\mathrm{CFU} / \mathrm{cm}^{2}\right)\right]$. The results were evaluated by analysis of variance (ANOVA) and the Tukey test $(\mathrm{P}<0.001)$.

\section{RESULTS}

The ability of this $P$. aeruginosa isolate to form biofilms was evaluated prior to the beginning of experiments using crystal violet (data not shown). The results demonstrated that all treatments were effective in disinfecting contact lenses storage cases $(\mathrm{P}<0.001)$, and the treatments with ozone and chlorhexidine can be considered the most efficient because they did not show P. aeruginosa in either of replicates (Table 1). The multipurpose solutions have also decreased the biofilm formation in 1.17 to $1.63 \mathrm{log}$ (92.93\% to $97.31 \%$ ) $\mathrm{CFU} / \mathrm{cm}^{2}$ (Figure 1), whereas ozone and chlorhexidine inactivated $P$. aeruginosa biofilm by a $7.34 \log (99.99999 \%)$ reduction.

There was significant difference in microbial $\log$ reduction between positive control and all treatments (Figure 1). There was no difference in microbial reduction percentage between treatments with ultrasound and solutions 1 and 2 . However, there were differences between multipurpose solutions or ultrasound when they were compared with ozone or chlorhexidine $(\mathrm{P}<0.001)$. 
Table 1 - Pseudomonas aeruginosa biofilm viability in cetrimide agar after the disinfection of contact lenses from the experimental cases.

\begin{tabular}{lc}
\hline Treatment & $\mathrm{CFU} / \mathrm{cm}^{2 \mathrm{a}} \pm \mathrm{SD}$ \\
\hline Positive control & $2.63 \pm 1.53 \times 10^{7}$ \\
Multipurpose solution 1 & $2.70 \pm 1.83 \times 10^{6 * \star *}$ \\
Multipurpose solution 2 & $6.12 \pm 1.94 \times 10^{5 * *}$ \\
Ultrasound & $1.27 \pm 0.25 \times 10^{* * *}$ \\
Ozone & $0.0^{* * *}$ \\
Chlorhexidine & $0.0^{* \star *}$ \\
\hline
\end{tabular}

a The colony forming units CFU (mean \pm standard deviation) derived from formed biofilms on the cavity of contact lens from the case $\left(\right.$ area $\left.=2.984513 \mathrm{~cm}^{2}\right)$. ${ }^{* * *}$ Mean values considered statistically different from positive control by the Tukey test when $\mathrm{P}<0.001$.

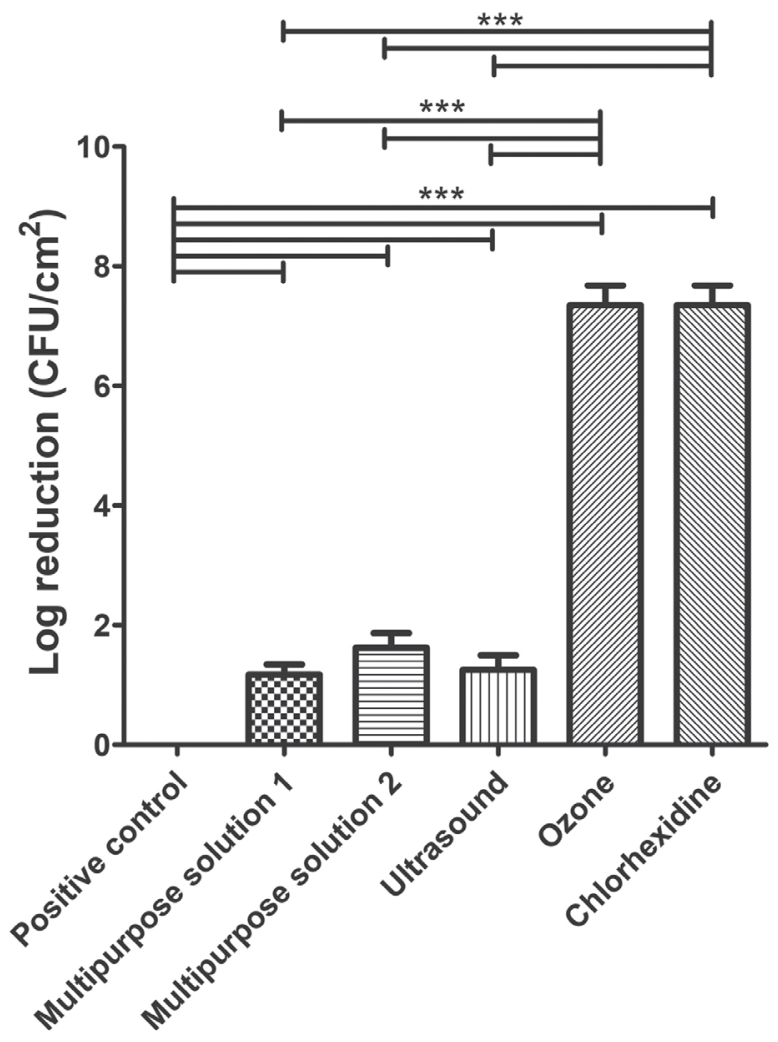

\section{Treatments}

Figure 1 - Log reduction of Pseudomonas aeruginosa biofilm cell viability after disinfection of contact lenses from experimental cases. Data are expressed as mean \pm SD (standard deviation). ${ }^{* * *}$ Mean values considered statistically different by the Tukey test when $\mathrm{P}<0.001$.

\section{DISCUSSION}

Previous studies have demonstrated that multipurpose solutions are not able to properly disinfect concentrations of bacteria as high as $10^{7} \mathrm{CFU} / \mathrm{mL}^{5,6}$. These solutions can usually reduce microorganisms by $10^{2-1} 0^{3} \mathrm{CFU} / \mathrm{mL}^{5,6}$. Similar to this work, previous studies demonstrated around $1 \log$ or $90 \%$ of $P$. aeruginosa biofilm reduction after disinfection with multipurpose solutions ${ }^{4,6,9}$. Therefore, these solutions should be used for the cleaning and maintenance of contact lenses before hand washing and manipulation of lenses. They are able to reduce biofilm formation especially in the initial stage of growth, up to 4 or $6 \mathrm{~h}^{10}$.

One of the alternative treatments used in this study was the ultrasound. It can produce pressure waves with a frequency of $20 \mathrm{kHz}$ or more, causing cavitation and generation of free radicals to inactivate microorganisms. Ultrasound processing is one of the alternative technologies that has shown promise in food industry and to achieve removal of microbial biofilms in medical devices ${ }^{11,12}$. Ultrasound at $25 \mathrm{kHz}$ in medical devices for 60 minutes reduces $99.99 \%$ of microbial contamination ${ }^{12}$.

An alternative treatment, chlorhexidine $0.12 \%$, showed a $7.42 \log$ efficiency. Chlorhexidine is used in antiseptic products due to its broad-spectrum of action against Gram positive and Gram negative bacteria and fungi. It is mainly for use on skin, where it produces low or no irritation ${ }^{13}$. Furthermore, chlorhexidine is able to remain linked in its active form to certain biological surfaces, such as the stratum corneum, acting as a reservoir of the antiseptic with prolonged bactericidal effect ${ }^{14}$. Chlorhexidine is also recommended for skin preparation before surgery and insertion of intravascular devices ${ }^{15}$. A study using $2 \%$ chlorhexidine demonstrated excellent antimicrobial activity for some microorganisms tested in their free form, but it was less effective against biofilms of $P$. aeruginosa ${ }^{16}$. Surfaces of leather and stainless steel cleaned with chlorhexidine in concentrations of $0.5 \%, 1 \%, 2 \%, 3 \%$ and $4 \%$ showed $100 \%$ reduction of $P$. aeruginos $a^{17}$. Although chlorhexidine skin preparation has been shown to provide highly effective antimicrobial pre-surgical skin cleansing, a recent study has demonstrated that there is a significant risk of ocular toxicity when $4 \%$ chlorhexidine gluconate is used in periocular areas $^{18}$. Further studies are still needed to verify whether the use of chlorhexidine in the disinfection of lenses storage cases would generate some residue and whether washing them with physiological serum could be sufficient to remove these residues.

Notably, ozonized water has also demonstrated a $7.42 \mathrm{log}$ efficiency in the inactivation of $P$. aeruginosa. Ozone has been used in disinfection of medical devices and food because it is highly reactive and does not leave harmful residues ${ }^{12,19}$. The ozone gas is a strong oxidant that promotes oxidation of aminoacids and proteins to alter cellular permeability, resulting in cell lysis ${ }^{20,21}$. The lipoprotein 
and lipopolysaccharide layers of Gram-negative bacteria are the main ozone targets, increasing the microorganism cell permeability, resulting in lysis ${ }^{20}$. Ozone inactivates $P$. aeruginosa by the combined results of increased cytoplasmic membrane permeability and cytoplasm coagulation $^{22}$. The effective concentration of ozone for disinfection of biofilms changes with the stage of biofilm formation ${ }^{23}$. Ozone is used for removal of $P$. aeruginosa on surfaces, which can dramatically reduce the count of living microorganism up to $100 \%{ }^{24}$. Furthermore, the application of ozone gas in medical devices at $33 \mathrm{mg} / \mathrm{L}$ for 15 minutes reduces at $5 \log (99.999 \%)$ of microbial contamination ${ }^{12}$. Thus, ozone efficiency in the removal of biofilms may depend on the roughness and composition of the surface to be disinfected, as well as the concentration of ozone and period of time of use.

In conclusion, we found that multipurpose solutions decreased biofilm formation, but did not eliminate it. Multipurpose solutions should be used to clean and preserve the lenses together with effective storage cases hygiene to minimize lenses storage case contamination and biofilm formation. We recommend washing and antisepsis of the hands, before manipulating contact lenses. The most effective treatments for reduction in formation of $P$. aeruginosa biofilm in contact lenses storage cases were ozonized water and chlorhexidine. Chlorhexidine use is popular, due to its high efficiency and broad availability, but more toxicity tests are necessary to examine residues remaining after treatment of lenses storage cases. As an alternative, ozone is particularly attractive because an ozonated water generator can be purchased for a low cost. Ozonation is an easy, fast and cost effective disinfection technique that can eliminate microbial biofilms due to its oxidative power; furthermore, it does not appear to form toxic residues.

\section{CONFLICT OF INTERESTS}

The authors report no conflicts of interest. The authors alone are responsible for the content and writing of the paper.

\section{ACKNOWLEDGMENTS}

Fundação de Amparo à Pesquisa do Estado de Minas Gerais (FAPEMIG) (APQ01413-12, APQ00507-14), Conselho Nacional de Desenvolvimento Científico e Tecnológico (CNPq) and Coordenação de Aperfeiçoamento de Pessoal de Nivel Superior (CAPES).

\section{REFERENCES}

1. Chi H, Chang KY, Chang HC, Chiu NC, Huang FY. Infections associated with indwelling ventriculostomy catheters in a teaching hospital. Int J Infect Dis. 2010;14:e216-9.

2. Diec J, Carnt N, Tilia D, Evans V, Rao V, Ozkan J, et al. Prompt diagnosis and treatment of microbial keratitis in a daily wear lens. Optom Vis Sci. 2009;86:E904-7.

3. Abidi SH, Sherwani SK, Siddiqui TR, Bashir A, Kazmi SU. Drug resistance profile and biofilm forming potential of Pseudomonas aeruginosa isolated from contact lenses in Karachi-Pakistan. BMC Ophthalmol. 2013;13:57.

4. Wu YT, Zhu H, Willcox M, Stapleton F. Removal of biofilm from contact lens storage cases. Invest Opthalmol Vis Sci. 2010;51:6329-33.

5. Ifejika CP, McLaughlin-Borlace L, Lucas VJ, Roberts AD, Walker JT. Efficacy of a contact lens cleaning device and its enhancement of the performance of contact lens care products. Br J Ophthalmol. 2000;84:539-41.

6. Lui AC, Netto AL, Silva CB, Hida R, Mendes TS, Lui GA, et al. Antimicrobial efficacy assessment of multi-use solution to disinfect hydrophilic contact lens, in vitro. Arq Bras Oftalmol. 2009;72:626-30.

7. Zhu H, Bandara MB, Vijay AK, Masoudi S, Wu D, Willcox MD. Importance of rub and rinse in use of multipurpose contact lens solution. Optom Vis Sci. 2011;88:967-72.

8. Rice EW, Baird RB, Eaton AD, Clesceri LS, editors. Standard methods for the examination of water and wastewater. $22^{\text {nd }}$ ed. Washington: American Public Health Association; 2012.

9. Laxmi Narayana B, Rao P, Bhat S, Vidyalakshmi K. Comparison of the antimicrobial efficacy of various contact lens solutions to inhibit the growth of Pseudomonas aeruginosa and Staphylococcus aureus. Int J Microbiol. 2018;2018:5916712.

10. Artini M, Cellini A, Scoarughi GL, Papa R, Tilotta M, Palma S, et al. Evaluation of contact lens multipurpose solutions on bacterial biofilm development. Eye Contact Lens. 2015;41:17782.

11. Piyasena P, Mohareb E, McKellar R. Inactivation of microbes using ultrasound: a review. Int J Food Microbiol. 2003;87:20716.

12. Lopes MS, Ferreira JR, da Silva KB, de Oliveira Bacelar Simplício I, de Lima CJ, Fernandes AB. Disinfection of corrugated tubing by ozone and ultrasound in mechanically ventilated tracheostomized patients. J Hosp Infect. 2015;90:304-9.

13. McDonnell G, Russell AD. Antiseptics and disinfectants: activity, action, and resistance. Clin Microbiol Rev. 1999;12:147-79.

14. Macias JH, Arreguin V, Munoz JM, Alvarez JA, Mosqueda JL, Macias AE. Chlorhexidine is a better antiseptic than povidone iodine and sodium hypochlorite because of its substantive effect. Am J Infect Control. 2013;41:634-7. 
15. Pronovost P, Needham D, Berenholtz S, Sinopoli D, Chu H, Cosgrove $\mathrm{S}$, et al. An intervention to decrease catheterrelated bloodstream infections in the ICU. N Engl J Med. 2006;355:2725-32.

16. Bonez PC, Alves CF, Dalmolin TV, Agertt VA, Mizdal CR, Flores $\mathrm{VC}$, et al. Chlorhexidine activity against bacterial biofilms. Am J Infect Control. 2013;41:e119-22.

17. Bambace AM, Barros EJ, Santos SS, Jorge AO. Eficácia de soluções aquosas de clorexidina para desinfecção de superfícies. Rev Biocienc. 2003;9:73-81.

18. Bever GJ, Brodie FL, Hwang DG. Corneal injury from presurgical chlorhexidine skin preparation. World Neurosurg. 2016;96:610. e1-4.

19. Oliver JC, Germano JL, Veiga SM. Eficiência de sanificantes alternativos sobre frutos contaminados artificialmente com Escherichia coli. Rev Univ Vale do Rio Verde. 2012;10:351-9.
20. Wysok B, Uradziński J, Gomółka-Pawlicka M. Ozone as an alternative disinfectant: a review. Pol J Food Nutr Sci. 2006; 15/56:3-8.

21. Victorin K. Review of the genotoxicity of ozone. Mutat Res. 1992;277:221-38.

22. Zhang YQ, Wu QP, Zhang JM, Yang XH. Effects of ozone on membrane permeability and ultrastructure in Pseudomonas aeruginosa. J Appl Microbiol. 2011;111:1006-15.

23. Tachikawa M, Yamanaka K, Nakamuro K. Studies on the disinfection and removal of biofilms by ozone water using an artificial microbial biofilm system. Ozone Sci Eng. 2009;31:3-9.

24. Klánová K, Lajèíková A. Use of ozone to reduce bacteria and moulds in the air and on surfaces. Indoor Built Environ. 2006;15:81-4 